\title{
Sobre la reconstitución del pensamiento crítico
}

Franz Hinkelammert

DEI

Costa Rica

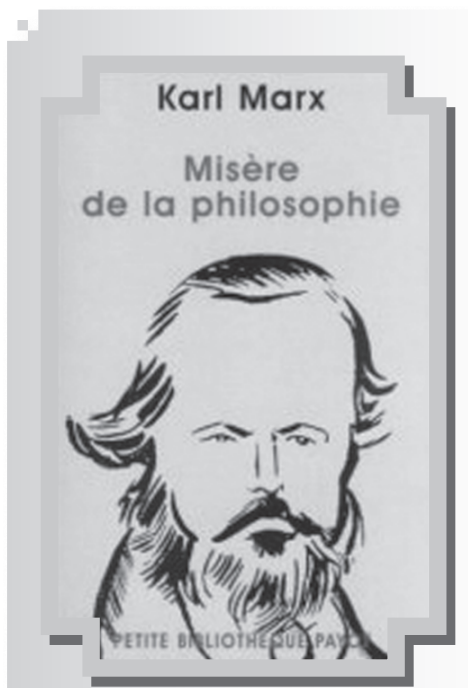

RESUMEN: Una reconstitución del pensamiento crítico implica una crítica del mismo. Pero no puede ser una ruptura con este pensamiento crítico, sino la elaboración de elementos de este, que han sido dejados de lado y que fueron marginados por otros. Por eso tiene que ser una crítica desde adentro, no crítica externa. Por eso, también se trata necesariamente también de una autocrítica.

ABSTRACT: Rebuilding critical thought implies its critic. But this critic can not be a rupture with that critical thought, but rethinking those elements that have been put apart by others. For that reason, this must be an inner critic, not an external one. That explains why it must be necessarily a self-critic. 
a reconstitución del pensamiento crítico no significa hacerlo completamente de nuevo o inventar algo completamente diferente. Una reconstitución es solamente posible en la continuidad. Pero rompe con elementos de este pensamiento crítico, que han sido considerados como centrales o esenciales y saca de eso sus consecuencias.

Una reconstitución del pensamiento crítico implica, por tanto, una crítica del pensamiento crítico, como se lo ha entendido hasta ahora. Pero no puede ser una ruptura con este pensamiento crítico, sino la elaboración de elementos de este, que han sido dejados de lado y que fueron marginados por otros. Por eso tiene que ser una crítica desde adentro, no crítica externa. Por eso, también se trata necesariamente también de una autocrítica.

Esta crítica como punto de partida de una reconstitución del pensamiento crítico tiene, como yo lo veo, dos direcciones principales.

Primero, la reconstitución de la economía política. Pero esta reconstitución tiene que tener como punto de partida la economía política burguesa de hoy, no la clásica. Por eso tiene que partir de las teorías económicas neoclásicas y neoliberales, para efectuar su crítica de la economía política desde allí. Con eso no se sustituye simplemente la crítica de la economía política de Marx. Pero se transforma en "clási$\mathrm{ca}^{\prime \prime}$, no directamente presente. Hay que hacerla presente en el mismo sentido como eso vale para todos los autores clásicos. Hay que apropiarla de nuevo desde hoy. Eso vale especialmente para el centro de la crítica de la economía política, que es la teoría del valor trabajo. No es una teoría de las cantidades de trabajo, sino una teoría del tiempo de trabajo. Como tal es una teoría del tiempo, que parte de un desdoblamiento del tiempo que es expresado como desdoblamiento de trabajo concreto y trabajo abstracto. La economía política burguesa de hoy ha reducido todo el tiempo a tiempo abstracto. El tiempo de la vida para ella es tiempo perdido. Esta economía política burguesa presente obliga a partir de la recuperación del tiempo de vida concreto, que no se puede reducir al tiempo de trabajo. Entonces se hace visible que el tiempo de trabajo del trabajo abstracto como parte del tiempo concreto de vida, transformado. En cambio el tiempo concreto del trabajo concreto atraviesa todo el tiempo de vida, lo que hace surgir un conflicto entre tiempo de trabajo abstracto y tiempo de vida. No se trata de ser y tiempo ni de tiempo y ser, sino de tiempo abstracto y tiempo de vida como tiempo concreto. Para eso Marx desarrolla los elementos decisivos. Pero hay que desarrollarlos desde nuestro presente, porque su sentido solamente se hace comprensible desde allí.

Eso nos lleva a la otra dirección principal de nuestra argumentación sobre una reconstitución del pensa- 
miento crítico. Se trata de aquello, que tradicionalmente ha sido denominado materialismo histórico. Formula el punto de partida del pensamiento crítico y por tanto también de la crítica de la economía política. Por eso, quiero concentrarme en las reflexiones que siguen en este punto.

\section{El materialismo histórico en su for- mulación clásica}

En la tradición marxista se concibe al materialismo histórico más bien desde un texto clásico de Marx, que casi siempre aparece. Se trata del prólogo del libro Para la crítica de la economía política del año 1859. Aquí se desarrolla la teoría de base y superestructura, en la cual existe una estructura económica, la tal Ilamada base, a la cual corresponde una superestructura, cuya dinámica está condicionada ${ }^{1}$ por la base. Esta base es se puede describir con "la fiabilidad de las ciencias naturales" y a ella corresponden las "formas ideológicas", a través de las cuales los seres humanos toman conciencia del conflicto existente en la base entre fuerzas productivas y relaciones de producción y a través de las cuales hacen sus conflictos: formas jurídicas, políticas, religiosas, de arte y filosóficas. Estas formas ideológicas reflejan en cierto sentido la base. Se trata de un análisis más bien de objetivización de esta relación, que ha tenido una influencia extraordinaria en casi todos los análisis posteriores sobre el materialismo histórico. Se mostraba sumamente adecuada para el pensamiento más bien burocrático de organizaciones políticas y partidos. Tiene como su fondo una imaginación abstracta del tiempo histórico.

Marx posteriormente no ha desarrollado más este análisis. Precisamente su desarrollo de la teoría del fetichismo ha ido más allá de este análisis en este su prólogo. A pesar de eso en los análisis sobre Marx y después de Marx las tesis del prólogo han sido tratados como la formulación clásica del materialismo histórico.

\section{El paso de Marx hacia una fenomenología de la vida real}

E n El capital (Tomo I) Marx cambia este punto de vista del prólogo de manera fundamental. Quisiera presenta precisamente esta formulación nueva, porque me parece necesaria para reconstituir hoy el materialismo histórico.

Quisiera partir de un texto tomado de El capital, en el cual esta relación de base y superestructura y de las formas institucionales e ideológicas correspondientes son vistas de una manera radicalmente diferente. Se trata efectivamente del paso hacia una fenomenología de la vida real:

"Las mercancías no pueden acudir ellas solas al mercado, ni cambiarse por sí mismas. Debemos, pues, volver la vista a sus guardia- 
nes, a los poseedores de mercancías. Las mercancías son cosas, y se hallan, por tanto, inermes frente al hombre. Si no se le someten de grado, el hombre puede emplear la fuerza o, dicho de otro modo, apoderarse de ellas. Para que estas cosas se relacionen las unas con las otras como mercancías, es necesario que sus guardianes se relacionen entre sí como personas cuyas voluntades moran en aquellos objetos, de tal modo que cada poseedor de una mercancía sólo puede apoderarse de la de otro por voluntad de éste y desprendiéndose de la suya propia; es decir, por medio de un acto de voluntad común a ambos. Es necesario, por consiguiente, que ambas personas se reconozcan como propietarios privados. Esta relación jurídica, que tiene como forma de expresión el contrato, es, hállese o no legalmente reglamentada, una relación de voluntad en que se refleja la relación económica. El contenido de esta relación jurídica o de voluntad lo da la relación económica misma. Aquí, las personas sólo existen las unas para las otras como representantes de sus mercancías, o lo que es lo mismo, como poseedores de mercancías." (Marx, Karl: El capital. FCE. México, 1966. I, p.48

Creo, que esta cita es de importancia central para la posterior comprensión del materialismo histórico de parte de Marx. El filósofo alemán no habla aquí de un condicionamiento de la superestructura por la base. Ni habla de una base en relación con una superestructura. En vez de eso, hay ahora relaciones entre cosas, que son mercancías (o pueden serlo potencialmente) y constituyen la relación económica (que indica ala vez relaciones de Propiedad y de producción) y que corresponde a la relación jurídica. Esta correspondencia la expresa como reflejo (en un espejo). Pero esta relación de reflejo tiene una dirección sorprendente: La relación económica - por tanto, la realidad vivida - tiene la relación jurídica como espejo y, por tanto, se refleja en la relación jurídica. La relación jurídica es el espejo, en el cual se ve y se refleja la relación económica. El prólogo de 1859 no habla de espejos o reflejos. Pero se refiere a una dirección del condicionamiento: la base condiciona a la superestructura. Pero ahora la relación es al revés y descrito como reflejo y en la cual el concepto de condicionamiento pierde su sentido: la relación jurídica es el espejo, en el cual se refleja la relación económica. Esta implica la realidad de la vida y da contenido material a las relaciones jurídicas.

Esta inversión de la relación, sin embargo, se nota ya en el propio año 1859. Marx no escribe solamente el prólogo sobre la crítica de la economía política, sino también una introducción, que no publicó y que se conoció recién muchos años después. En esta introducción ya se encuentran muchas tendencias hacia esta otra forma de concebir el materialismo histórico. Eso ocu- 
rre especialmente en la discusión de la relación entre producción y consumo.

En su análisis en El capital esta teoría del reflejo es el resultado de su análisis de la forma mercancía en el anterior análisis de la teoría del valor. Pero no efectúa una simple abolición de la teoría del condicionamiento de la superestructura por la base, sino emprende un camino diferente: toma ahora como punto de partida la realidad de la vida. Por eso, desarrolla la relación a partir del sujeto humano concreto. Por eso se trata del resultado de su teoría del fetichismo.

Cuando posteriormente en el análisis marxista aparece la palabra reflejo, no mantiene el significado que Marx le da. Es interpretado en el sentido de un condicionamiento o hasta de una determinación de la superestructura por la base, lo que ocurre especialmente en Lenin. La teoría del reflejo de Marx prácticamente desaparece de la tradición marxista. Pero es esta la teoría que continúa el humanismo de Marx.

El texto arriba citado normalmente es leído de una manera tal como si fuera una simple repetición del prólogo de 1859. Eso puede mostrar una cita del marxista francés Bidet, cuyo libro sobre la teoría de la modernidad ha sido discutido mucho en América Latina y que se refiere a este mismo texto:

"Este paradigma del 'reflejo', plantea, evidentemente, algunos problemas. Remite a dos repre- sentaciones conexas que quisiera analizar sucesivamente. La de efecto, según la cual lo jurídico parece predeterminado por lo económico. La de apariencia, que encontramos en la imagen de la máscara y de modo más general en la metáfora de la superficie". ${ }^{2}$

"El efecto teórico de este procedimiento es evidente. Pone en primer plano la relación denominada aquí 'económica', definida por las formas categoriales de la mercancía. Permite presentar las relaciones entre personas, y en todos los casos las relaciones jurídicas, como elementos subsecuentes, como 'reflejos' de las relaciones económicas entre cosas". (p. 143)

Pero Marx en el texto citado no determina lo jurídico por lo económico. Marx dice expresamente que se ve la relación económica en el espejo del derecho, de lo jurídico. Eso es lo contrario de lo que sostiene Bidet. Tampoco la superficie o la máscara, cuando Marx se refiere a estos, no significan, como cree Bidet, "pura" superficie. No ve, que Marx parte del sujeto vivo que evidentemente puede ver solamente esta superficie de los fenómenos. Pero que el mundo es subjetivo, también para Marx es una hecho objetivo y no una simple imaginación. La lectura de Bidet no toma siquiera el texto de Marx en serio, sino le impone a la fuerza las categorías del prólogo de 1859, que Marx precisamente rompe. Eso, sin embargo, no es solamente un problema de Bidet, sino vale e general 
para la lectura de este texto en la tradición marxista.

Esta presencia objetivada de las relaciones jurídicas en el objetomercancía Marx la Ilama fetichismo. Lo analiza en sus etapas como fetichismo de la mercancía, del dinero y del capital. Pero la llave es su teoría del espejo, que es lo contrario de aquello, que el marxismo ortodoxo se había imaginado con su teoría del reflejo, que sigue siendo una teoría de la superestructura.

Pero Marx dice exactamente lo contrario de lo que se le imputa en tal teoría del reflejo. Marx de ninguna manera afirma que las relaciones jurídicas son el simple reflejo de las relaciones económicas. Incluso sostiene lo contrario, es decir, que las relaciones económicas son el reflejo (la imagen especular) de las relaciones jurídicas, en el sentido de que sólo resultan visibles en tanto imagen especular reflejada/conformado por las relaciones jurídicas. Pero lo dice con la palabra "wiederspiegeln", lo que significa, reflejarse en el espejo o, si se quiere "espejar". Por tanto, la tesis de Marx es que vemos las relaciones económicas en un espejo y no directamente. Las vemos en el espejo constituido por la relación jurídica, que de su parte está constituida por los hombres en cuanto hacen morar su voluntad en los objetos. Eso ocurre en cuanto se hacen propietarios al reconocerse mutuamente como tales y consideran el objeto de propiedad suya. Dice en el texto citado:

\section{"Esta relación jurídica... [en forma de un espejo] es, ... una relación de voluntad en que se refleja la relación económica".}

Sin duda, la relación jurídica es vista como el espejo, en el cual la relación económica se refleja. Ya antes, en el capítulo primero de $E I$ capital, ha desarrollado la tesis de que la relación económica, reflejada en el espejo de la relación jurídica, es vista - como siempre ocurre con la imagen en un espejo- de manera invertida, de lo cual se deriva su teoría del fetichismo mercantil. En este sentido, la relación económica es el reflejo de la relación jurídica. Lo es como forma del contrato de compra-venta. Solamente el contenido del contrato viene de la relación económica misma, esto es, el valor de uso también envuelto en la forma mercantil. El contenido se refiere a las mercancías específicas, que se compran y se venden. No puede resultar de la forma del contrato, es decir, de la forma jurídica. Sigue el mismo texto citado:

"El contenido de esta relación jurídica o de voluntad lo da la relación económica misma" 
Marx además ha dicho en el mismo texto citado, como él entiende el surgimiento de las relaciones

económicas como reflejo de las relaciones jurídicas:

"Para que estas cosas se relacionen las unas con las otras como mercancías, es necesario que sus guardianes se relacionen entre sí como personas cuyas voluntades moran en aquellos objetos, de tal modo que cada poseedor de una mercancía sólo puede apoderarse de la de otro por voluntad de éste y desprendiéndose de la suya propia; es decir, por medio de un acto de voluntad común a ambos. Es necesario, por consiguiente, que ambas personas se reconozcan como propietarios privados."

Esta parte es básica para entender la relación económica como el reflejo de la relación jurídica. Debe haber una penetración del mundo de los objetos por la relación jurídica. Esta se da en cuanto los poseedores de los objetos hacen morar su voluntad en ellos. Con eso constituyen su esfera privada, con el resultado de que "cada poseedor de una mercancía sólo puede apoderarse de la de otro por voluntad de éste y desprendiéndose de la suya propia; es decir, por medio de un acto de voluntad común a ambos." Este acto de voluntad es el contrato. Ahora los objetos son mercancías y sus poseedores se reconocen mutuamente como propietarios.

Cuando el mundo de los objetos es propiedad privada, porque cada objeto tiene un propietario, cuya voluntad mora en él, entonces la relación jurídica está objetivamente presente en el objeto. Hacer morar la voluntad en los objetos es un acto subjetivo. Pero se trata de una subjetividad que constituye hechos obje- tivos. La propia subjetividad resulta ser algo objetivo. El objeto en su existencia objetiva de mercancía refleja ahora esta relación jurídica. Por tanto, los propietarios no se pueden relacionar en cuanto propietarios sino relacionando los objetos, sobre los cuales tienen propiedad. Esta relación entre los objetos-mercancías también llega a tener objetividad. Evidencia objetivamente, cómo los objetos se intercambian, es decir, qué equivalencias de intercambio tienen. La mercancía es constituida objetivamente, en cuanto la voluntad de los poseedores mora en ella, y ocurre un reconocimiento entre los hombres, en el cual se reconocen como propietarios.

Es ahora obvio, que el contenido de las relaciones jurídicas no puede venir de las mismas relaciones jurídicas. En cuanto se trata de objetos, en los cuales mora la voluntad del propietario, estos objetos dan los contenidos. Pero en cuanto objetos, ahora son mercancías, o lo son por lo menos en potencia. 
Un objeto, en el cual no mora ninguna voluntad de ningún propietario, es una objeto abandonado, tirado. No es mercancía, sino objeto botado, por ejemplo, la basura. En este estado cualquier persona puede apropiarse de él. Sin embargo, si alguien se apropia de este objeto, hace morar su voluntad en él, y se vuelve a presentar como una mercancía, que es propiedad de aquél que se adueñó del objeto. En este sentido, la diferencia entre un objeto abandonado, del cual cualquiera puede apropiarse, y un objeto mercancía, es en última instancia jurídica. Pero los objetos reflejan esta relación jurídica de una manera tal, que nosotros con nuestros sentidos podemos distinguir entre objetos abandonados y objetos que son propiedad de alguien. Además, es peligroso no hacer la distinción, porque la policía vigila cualquier violación a la propiedad privada. Por eso, el objeto abandonado lo es objetiva y visiblemente, aunque ningún carácter corporal del objeto permite discernirlo. El objeto refleja para nosotros su condición jurídica.

Sin embargo, esta objetividad con la cual las cosas-mercancías se reflejan en el espejo de la relación jurídica, ahora se devuelve a los ojos del hombre, quien las mira. Al verlas, las vemos reflejadas como mercancías a partir de las cuales constituimos nuestra visión del mundo. No vemos nunca directamente el objeto, sino solamente a un objeto reflejado en el espejo de la relación jurídica.

"La conducta puramente atomística de los hombres en su proceso social de producción, y, por tanto, la forma material (sachlich-forma-cosa) que revisten sus propias relaciones de producción, sustraídas a su control y a sus actos individuales concientes, se revelan ante todo en el hecho de que los productos de su trabajo revisten, con carácter general, forma de mercancías." (Marx, Karl: El capital. FCE. Mexico, 1966. I, p.55)

De esta manera vuelve el reflejo. El reflejo es reflejado:

"El carácter misterioso de la forma mercancía estriba, por tanto, pura y simplemente, en que proyecta [zurückspiegelt; en este caso, la forma mercantil es el espejo] ante los hombres el carácter social del trabajo de éstos como si fuese un carácter material de los propios productos de su trabajo, un don natural social de estos objetos y como si, por tanto, la relación social que media entre los productores y el trabajo colectivo de la sociedad fuese una relación social estableci- 
da entre los mismos objetos, al margen de los productores." (Marx, op.cit. I, p.37)

El objeto deja de ser perceptible como un producto del trabajo colectivo. Lo social pasa a las mercancías, que ahora es intercambiabilidad. Sin embargo, las personas, al reconocerse como propietarios, establecen relaciones entre ellas, que son dominadas por la relacióncosa (sachlich-material).
Las "relaciones de producción" - cuya forma es la relación jurídica misma- están en las cosas, en cuanto que son mercancías. Pero la mercancía no las revela como tales, sino en forma sustraída a sus actos individuales concientes.

El mundo está ahora al revés:

"Lo que aquí reviste, a los ojos de los hombres, la forma fantasmagórica de una relación entre objetos materiales no es más que una relación social concreta establecida entre los mismos hombres." (Marx, op.cit. I, p.38)

Subyace a todo este análisis el tipo de reconocimiento humano implicado en las relaciones jurídicas de la sociedad mercantil. Las personas se reconocen mutuamente como propietarios, y como tales establecen entre sí relaciones contractuales. El contrato es la forma más visible de este reconocimiento. Pero este reconocimiento de las personas como propietarios - que es la relación jurídica misma- está como reflejo ya en las mercancías, que reflejan, al hacerse mercancías, esta relación jurídica, que es el espejo. Una vez constituido el mundo como mundo de mercancías, el reflejo de este mundo en la mente refleja a la persona como propietario. Lo es ahora, porque la realidad del mundo mercantil lo confirma. Pero el mundo mercantil lo confirma porque ya objetivamente ha reflejado este reconocimiento mutuo entre las personas como propietarios. Se hace individuo. $Y$ el mundo de las mercancías lo confirma al reflejar objetivamente el reconocimiento entre las personas como propietarios. El ser humano se hace individuo por esta razón. Lo que reflejan las cosas en el espejo de las relaciones jurídicas, el individuo lo internaliza y reproduce.

\section{I.I EI reflejo del reflejo}

Eso es, lo que refleja este espejo de las relaciones jurídicas. Vemos en ellas la forma mercancía como lo que es. En el espejo de las relaciones jurídicas aparecen entonces las formas imaginarias de la producción de mercancías, que Marx Ilama el verdadero Edén de los derechos humanos. So el reflejo del reflejo, la forma fantasmagórica de la producción mercantil: 
La órbita de la circulación o del cambio de mercancías, dentro de cuyas fronteras se desarrolla la compra y la venta de la fuerza de trabajo, era, en realidad, el verdadero paraíso de los derechos del hombre. Dentro de estos linderos, solo reinan la libertad, la igualdad, la propiedad y Bentham. La libertad, pues el comprador y el vendedor de una mercancía, v. gr. de la fuerza de trabajo, no obedecen a mas ley que la de su libre voluntad. Contratan como hombres libres e iguales ante la ley. El contrato es el resultado final en que sus voluntades cobran una expresión jurídica común. La igualdad, pues compradores y vendedores sólo contratan como poseedores de mercancías, cambiando equivalente por equivalente. La propiedad, pues cada cual dispone y solamente puede disponer de lo que es suyo. $Y$ Bentham, pues a cuantos intervienen en estos actos sólo los mueve su interés. La única fuerza que los une y los pone en relación es la fuerza de su egoísmo, de su provecho personal, de su in- terés privado. Precisamente por eso, porque cada cual cuida solamente de sí y ninguno vela por los demás, contribuyen todos ellos, gracias a una armonía preestablecida de las cosas o bajo los auspicios de una providencia omniastuta, a realizar la obra de su provecho mutuo, de su conveniencia colectiva, de su interés general. ${ }^{3}$

Lo que Marx no menciona todavía es la construcción formalizada de estas relaciones mercantiles en el tal Ilamado modelo de la competencia perfecta. Ella aparece recién hacia el final del siglo XIX. Por eso Marx no la podía conocer todavía.

Eso es, lo que se ve en un espejo y este espejo son las relaciones jurídicas. Lo imaginario es dimensión de lo que efectivamente es. Por eso no es superestructura. Es el reflejo del reflejo, su dimensión imaginaria.

\section{I.2 La presencia de una ausencia}

Eso implica una inversión del mundo, que produce precisamente el espejo mismo:

"... las relaciones sociales que se establecen entre sus trabajos privados aparecen como lo que son: es decir, no como relaciones directamente sociales de las personas en sus trabajos, sino como relaciones materiales [sachliche! e.d. con carácter de cosas] entre personas y relaciones sociales entre cosas." (Marx, op.cit. l, p.38, subrayado nuestro)

Aparecen como lo que son! La realidad aparece en la empiria inmediata como lo que es. Se ha establecido un círculo. Lo que aparece como lo que es, es él mismo, un reflejo hecho objetivo en la mercancía. Resulta, que la relación jurídica coincide con la realidad, porque la realidad refleja objetivamente esta misma relación jurídica. Interpretar 
esta realidad como realidad última, resultará necesariamente en la confirmación de su supuesto constituyente: el reconocimiento mutuo de las personas como propietarios. Se trata de un quid pro quo, un círculo vicioso. La realidad confirma las relaciones jurídicas precisamente porque las refleja objetivamente $y$ realmente.

Pero en cuanto las personas se reconocen como propietarios, no se reconocen como sujetos en cuanto que sujetos de necesidades (como relaciones directamente sociales de las personas en sus trabajos). Al aparecer las relaciones sociales como lo que son, son "relaciones materiales (sachliche! e.d. con carácter de cosas) entre personas y relaciones sociales entre cosas".
Pero no aparece, cuando las relaciones sociales aparecen como lo que son, lo que estas relaciones sociales no son, es decir "relaciones directamente sociales de las personas en sus trabajos". Lo que esta realidad no es, es una ausencia presente, una ausencia que grita y que cada uno de los participantes en el mercado vive.

Aquí resulta el punto de vista, bajo el cual Marx juzga: la ciencia tiene que escuchar este grito, que le viene de la ausencia presente de lo que está escondido, condicionando todo. En las "relaciones directamente sociales de las personas en sus trabajos", la producción de valores de uso sería visiblemente lo que realmente es y dejaría de ser una ausencia presente:

\section{"... la asimilación de las materias naturales al servicio de las necesidades humanas, la condición general del intercambio de materias entre la naturaleza y el hombre, la condición natural eterna de la vida humana" (Marx, op cit. I, p.136)}

Las personas se reconocerían como sujetos de necesidades. La sociedad mercantil abstrae de esta dimensión humana (por eso es, según Marx, antihumana), precisamente en nombre de lo que es. Sin embargo, la teoría del fetichismo demuestra precisamente, que esta referencia a lo que es, es una simple tautología. Se extrae de la realidad lo que previamente se ha introducido en ella. Pero esta dimensión humana presente por ausencia es objetiva y por tanto su reconocimiento es necesario. No puede haber ciencia más allá de la ciencia ideologizada sin este reconocimiento.

Marx supone siempre que este paso hacia relaciones sociales directas" como relaciones directamente sociales de las personas en sus trabajos" es algo posible. Yo supongo, en cambio, que se trata de algo imposible y que eso hace ver un límite de la misma conditio humana. Pero eso no es decisivo. Si no es un paso posible, resulta un conflicto permanente con continuamente necesarias mediaciones en pos de una humanización de las relaciones humanas. 
Lo decisivo es el punto de vista bajo el cual Marx analiza. Posibilita juicios críticos sobre lo que es y su posible cambio. Se trata de este punto de vista que recién hace posible un pensamiento crítico. Pero no se trata de valores cualesquiera, que se introduce desde afuera a la realidad, sino de la ausencia presente de otro mundo, que hace falta hacer presente y que tiene que atravesar el mundo dado.

Se trata de una dialéctica de la presencia de una ausencia, que no es hegeliano. De hecho se trata de una dialéctica trascendental, para la cual las relaciones sociales directas — como relaciones directamente sociales de las personas en sus trabajos - son la referencia trascendental. Resulta una ética, que no es ética de normas, sino que formula un punto de vista najo el cual cualquier ética de normas es criticable y desarrollable. ${ }^{4}$ Trascendental significa aquí lo imposible, que hace posible ver los posible. Para Kant lo trascendental sería algo no empírico que es condición de posibilidad de lo empírico. Es el punto de vista del observador y por tanto estático. Aquí se trata del punto de vista del ser humano actuante y de la praxis. Por tanto, lo trascendental es lo imposible. La trascendentalidad es subjetiva. En la física esta trascendentalidad es el perpetuum mobile (en la economía neoclásica la "competencia perfecta"), en el pensamiento crítico es "relaciones directamente sociales de las personas en sus trabajos". Lo primero se expresa en conceptos trascendentales, lo segundo son reeferencias trascendentales, que no se pueden conceptualizar. Eso es necesario, por que trascienden el propio mundo de los conceptos, del argumento discursivo y de la razón instrumental medio-fin.

Marx llega de esta manera a un punto de vista que ya había formulado como joven Marx. Habló del "imperativo categórico de echar por tierra todas las relaciones en que el hombre sea un ser humillado, sojuzgado, abandonado y despreciable" (Fromm, Erich: Marx y su concepto del hombre ${ }^{5}$ ). Este punto de vista sigue el mismo, pero ahora es desarrollado con otras palabras desde el interior de la crítica de la producción de mercancías. El joven Marx habló en el mismo contexto del ser humano como "el ser supremo para el ser humano". Ahora el paso a relaciones sociales directas es la condición para que el ser humano puede realizar su humanidad. El ser humano sigue siendo "el ser supremo para el ser humano".

Lo que está presente por su ausencia es precisamente eso", el ser humano como el ser supremo para el ser humano. Marx le puede dar otros nombres como "relaciones directamente sociales de las personas en sus trabajos" o "reino de la libertad".

Pero esta referencia trascendental es también presente de una manera negativa. 
Libertad e igualdad son, en cuanto son definidas en el marco de las relaciones jurídicas, en el mismo acto, en el cual hacen presente libertad e igualdad, mecanismos de la explotación y dominación. Tienen eso como el otro lado sencillamente porque no son "relaciones directamente sociales de las personas en sus trabajos". Por eso, su ausencia está presente en las relaciones jurídicas y en la realidad que se refleja en ellas. Son igualmente presentes en la explotación y la dominación, en las cuales su ausencia grita al cielo. Eso es el grito del sujeto. El cielo, al cual grita, es precisamente esta ausencia de "relaciones directamente sociales de las personas en sus trabajos".

Por tanto, después del texto citado en el cual Marx habla de "libertad, igualdad y Bentham", puede hablar del drama resultante:

Al abandonar esta órbita de la circulación simple o cambio de mercancías, donde el librecambista vulgaris va a buscar las ideas, los conceptos y los criterios para enjuiciar la sociedad del capital y del trabajo asalariado, parece como si cambiase algo la fisónoma de los personajes de nuestro drama. EI antiguo poseedor de dinero abre la marcha convertido en capitalista, y tras el viene el poseedor de la fuerza de trabajo, transformado en obrero suyo; aquél, pisando recio y sonriendo desdeñoso, todo ajetreado; éste, tímido y receloso, de mala gana, como quien va a vender su propia pelleja y sabe la suerte que le aguar- da: que se la curtan. Marx, Carlos: El capital. FCE, México, pp.128-129

Eso es la presencia de lo contrario de aquello, que es presente por su ausencia, es decir, de las relaciones directas entre las personas. Pero tampoco esta realidad es visible en el espejo formado por las relaciones jurídicas: en este espejo solamente aparecen libertad, igualdad y Bentham.

Pero, ¿cómo llegan a ser visibles? Llegan a ser visibles, en cuanto se forma el juicio a partir de la ausencia presente. Si solamente se ve lo que es, no se ve este contrario tampoco.

Si se hace invisible esta presencia de la ausencia, para ver solamente lo que es y no lo que no es, entonces, entonces no se hace visible como y de que manera lo contrario de libertad, igualdad y Bentham está realmente presente. En el espejo de las relaciones jurídicas no aparece esta realidad invertida. Todo parece ser natural.

Desde el punto de vista de aquello, que es presente por su ausencia recién se hace visible

Libertad, igualdad y Bentham están presentes siempre también por su contrario. La presencia de la ausencia, desde la cual todo eso se hace visible, resulta de la negación de libertad e igualdad por su contrario, es decir, por explotación y dominación, que está presente en su interior e inseparable de ellas. Por eso, esta ausencia es el fundamento. 
Libertad, igualdad y Bentham siempre están presentes también por su contrario y en este sentido ausentes. Pero esta ausencia no se puede hacer presente solamente, en cuanto se hace presente la ausencia fundamental. De otra manera resulta una ilusión. Es quiere decir, que se trata de "echar por tierra todas las relaciones en que el hombre sea un ser humillado, sojuzgado, abandonado y despreciable." Eso es el significado del imperativo categórico de Marx. Es una ruptura con el humanismo burgués que cree, poder humanizar las relaciones humanas por una simple ampliación de libertad, igualdad y Bentham.

\subsection{Lo humano y su presencia}

La presencia de una ausencia, lo que no es, pero que está presente, eso es la llave. Esta ausencia es lo humano, que siempre, aunque sea como ausencia, está presente. En las mismas estructuras de dominación ocurre esta presencia. Se puede tratar a un ser humano inhumanamente, pero no se lo puede tratar como un animal. Deshumanizar a seres humanos, es algo específicamente humano. Si se tratara a un ser humano como un animal, no se lo puede esclavizar. Porque se escaparía o se defendería.

Deshumanizar, sojuzgar, abandonar y despreciar a un ser humano, presupone mecanismos de dominación, que hacen presente lo que no es, es decir su reconocimiento como ser humano. De una manera no-intencional tienen que reconocer que es un ser humano y no un esclavo, para poder esclavizarlo. ${ }^{67}$ Sin saber que el ser humano no es esclavo, no puede funcionar la estructura de dominación del esclavismo. Eso es la contradicción interna que atraviesa todas las estructuras de dominación. Tampoco se puede odiar a un animal tanto como se puede odiar a un ser humano. Para eso tendría que suponerse que sea un ser humano.

Se puede deshumanizar al ser humano, pero no se lo puede tratar como animal o hacerlo un animal. También en el extremo más deshumanizante sigue siendo un ser humano deshumanizado, y las formas de deshumanizarlo revelan, que hasta el que lo oprime sabe muy bien que es un ser humano, cuya humanidad está negando. También un animal o la naturaleza se puede solamente deshumanizar y no "desanimalizar" o "desnaturalizar". Las formas de la deshumanización muestran, que el deshumanizado es un ser humano deshumanizado, y el mismo opresor lo sabe y tiene que saberlo, para poderlo oprimir. Por eso la recuperación de lo humano es y tiene que incluir la humanización de la relación humana con la naturaleza. No se puede derivar nada de la naturaleza como tal, no puede haber derechos naturales o de la naturaleza de por sí. La exigencia de la humanización resulta de las relaciones entre los seres humanos y de ellos con la naturaleza externa, es la exigencia de hacer presente aquello, que está presente por ausencia en estas relaciones. 
A partir de eso, por supuesto, se puede adjudicar también a la naturaleza derechos. Análisis de este tipo los encontramos especialmente en Sartre.

Eso se refiere al ser humano entero. Marx lo tiene presente, cuando dice por ejemplo, que el hambre que se satisface con tenedor y cuchillo, es un hambre muy distinto del hambre que se satisface devorando la comida. El ser humano no es un animal vocale o un animal intelectuales. En todas sus expresiones corporales, en la manera de comer, de beber, de vestirse, de tener casa, de tener relaciones sexuales, de caminar, de bailar es un ser humano, no un animal. Por eso puede ser deshumanizado en todas las expresiones de su vida y es deshumanizado de esta manera. Y siempre las formas de esta deshumanización revelan, que se trata de un ser humano y que aquél, que lo deshumaniza, sabe que es un ser humano y no un animal. Sin saber eso, no podría negar su humanidad. Y siempre está presente la humanidad negada en su forma de ausencia que grita. El ser humano no tiene la corporeidad en común con el animal, para distinguirse del animal por su alma, su hablar o por su intelecto. Precisamente se distingue por su corporeidad del animal. Esta corporeidad humana por supuesto incluye su hablar, su pensar y su alma.

Lo que es, son los mecanismos de dominación. Lo que no es, es aquello negado por los mecanismos de dominación, es decir, su libertad como reconocimiento positivo de "relaciones directamente sociales de las personas en sus trabajos" y del hecho, de que "el ser humano es el ser supremo para el ser humano". En su forma negada, como presencia de su ausencia, siempre están porque su negación revela lo que está negado. Lo negado no está en el exterior, sino está en el interior de las relaciones de dominación. Estas son lo que es, y de ellas se puede derivar, lo que no es, porque es negado. Negation positio est.

Resulta un humanismo, que no surge en nombre de alguna llamada de "esencia" humana, sino que surge desde el interior de las propias relaciones humanas. Está dado objetivamente, no es una ética que irrumpe desde afuera en las relaciones humanas. La ética que surge no tiene un Sinaí externo, sino está dada con la misma realidad. Su Sinaí es lo interior de la realidad.

Creo que aquí se trata de la última instancia de lo que Marx Ilama el materialismo histórico. Engels lo reduce cuando dice:

"Según la concepción materialista de la historia, el factor que en última instancia determina la historia es la producción y reproducción de la vida real. Ni Marx ni yo hemos afirmado nunca más que esto". (Carta de Engels a J. Bloch, 21-22 de septiembre de 1890).

Marx dijo más. En Engels desaparece la presencia de la ausencia de relaciones sociales directas entre las personas, que recién fundamenta 
el papel de la "producción y reproducción de la vida real".

Solamente a partir de la presencia de una ausencia se puede entender porque Marx se concentra cada vez más en el análisis de las estructuras de dominación del capitalismo. Estas relaciones de dominación como lo que es revelan lo que no es, es decir, que el ser humano no es reconocido como ser humano, sino que es deshumanizado.

No aparece ninguna ruptura entre el humanismo del joven Marx y del Marx de El capital, como lo creía Althusser. El propio joven Marx rompe con el humanismo burgués. La consecuencia es, que posteriormente se concentra en el análisis de las estructuras de dominación capitalistas y hacer visible de esta manera la presencia de la ausencia del reconocimiento positivo de la humanidad del ser humano. El joven Marx ya destaca lo que también está presente en todo El capital: "echar por tierra todas las relaciones en que el hombre sea un ser humillado, sojuzgado, abandonado y despreciable."

Aquí no hay nada del humanismo burgués sea de Feuerbach o sea de la economía política clásica burguesa. Es el llamado de indicar $y$, por consiguiente, cambiar todas las relaciones —se trata de las relaciones de dominación-, en las cuales el ser humano es "un ser humillado, sojuzgado, abandonado y despreciable." Eso es precisamente lo que Marx hace en El capital.
Si se ve allí una ruptura, significa solamente que no se ha entendido nada y se descubre en el Marx de El capital solamente restos de humanismo que hay que superar. Marx es transformado en un estructuralista sin perspectiva y sin visión. Es ahora un ortodoxo.

Considero, que una reconstitución tendría que partir de una tal comprensión del materialismo histórico de parte de Marx. Tiene que tener como su punto de partida precisamente la presencia de una ausencia de relaciones humanas directas, la cual se hace patente como una deshumanización del ser humano en las estructuras de las relaciones de dominación capitalistas presentes. Estas estructuras son el espejo, en el cual esta ausencia se revela. Partiendo de eso puede efectuar la crítica de la economía política burguesa actual, que tiene que partir de esta economía política actual —es decir, de la teoría económica neoclásica y neoliberalpara demostrar esta negación de lo humano, como aparece en este pensamiento económico. Cada pensamiento económico muestra esta ausencia, aunque sea solamente para esconderla. Se trata de aquello que Marx realizó con la economía política clásica, cuya simple repetición desembocaría solamente en una escolástica vacía.

La teoría del fetichismo de Marx sostiene que para una ciencia en la cual las relaciones de dominación -las instituciones - aparecen simplemente como lo que son, la 
misma realidad llega a ser invisible. No tiene más que una empiria. De esta manera se le escapa precisamente todo lo que es condición de la vida. Se trata de la condición, que solamente puede ser derivada a partir de la presencia de una ausencia, que en la vida de todos y de cada uno es vivida. Sin embargo, la teoría la excluye. La excluye al decir solamente lo que es. Eso le permite ser útil en las prácticas de la vida normal para entender la manera de actuar de aquellos, que se mueven en una sociedad mercantil adaptándose simplemente a ella.

De esta manera la teoría del fetichismo es una teoría científica y no una teoría en el "orden ideológico". Como teoría científica puede explicar precisamente la producción social de ideologías específicas en relación con la producción de mercancías.

De esta manera resulta, que se ve la "relación económica" siempre en un espejo, que es la relación jurídica (y con eso la estructura de propiedad y las relaciones de dominación en general). Por eso se las ve de manera invertida. Esta realidad esconde la realidad de la vida real, que grita que condiciona todo y que solamente puede ser comprendida desde la presencia de una ausencia. Por eso demuestra Marx como el resultado de su crítica de la economía que, si no se hace positivamente presente esta realidad de la vida real, para que atraviese por lo menos la realidad vista en el espejo, resulta un proceso autodestructivo que amenaza la vida misma:

"Por tanto, la producción capitalista sólo sabe desarrollar la técnica y la combinación del proceso social de producción socavando al mismo tiempo las dos fuentes originales de toda riqueza: la tierra y el trabajador". ${ }^{8}$

\section{I.4 La parábola de la caverna y la teoría del espejo}

Esta teoría del espejo es visiblemente un desarrollo de la parábola de la caverna de Platón. Pero no es igual. En la parábola de la caverna los seres humanos ven al mundo como la sombra al sol de las ideas. No aparecen como se ven uno al otro. En Marx, en cambio, la relación entre los seres humanos es tal, que se transforma por la relación jurídica en el espejo en el cual se ven mutuamente y el mundo exterior de las cosas. El obstáculo para el conocimiento se ha hecho subjetivo a pesar de que esta subjetividad es objetivamente válida y presumiblemente inevitable. Que el mundo es subjetivo se descubre como un hecho objetivo. La relación jurídica y, por tanto, la forma mercantil hacen como espejo un mundo en este espejo, cuya realidad es falsa y que hay que trascender para percibir la realidad misma como realidad de la vida real. 
El paso de la parábola de la caverna hacia esta visión subjetiva del mundo como reflejo en un espejo, detrás del cual se puede percibir la realidad de la vida, aparece ya anteriormente en San Pablo cuando dice:

"Ahora vemos en un espejo, en enigma. Entonces veremos cara a cara. Ahora conozco de un modo parcial, pero entonces conoceré como soy conocido."1 Cor. 13,12

Este conocimiento es un conocimiento entre uno y otro, por tanto mutuo, y también para San Pablo el espejo, que hace enigmático el conocimiento, es la ley. Si para Platón el cuerpo es la cárcel del alma, ya para San Pablo la ley es la cárcel del cuerpo.

Marx desarrolla esta subjetivización hacia la ley del valor, que para Marx es la cárcel del cuerpo.

Se puede ampliar este punto de vista de Marx y me parece necesario hacerlo. No solamente la relación jurídica, que da la forma a las relaciones mercantiles, es un espejo en el cual se refleja la relación económica. Parece que se trata de mucho más. Todo el sistema institucional es un tal espejo, en el cual se refleja el mundo entero $y$ no podemos ver el mundo sin verlo como un mundo, que se refleja en el espejo del sistema institucional, en total o parcialmente. Lo que no es visible es la presencia de la ausencia de otro mundo que está como ausencia y es como tal pensada, soñada, desarrollada como mito y que también es hecha presente positivamente como trato humano entre seres humanos. Pero siempre es válida la conclusión que, si no se logra hacer presente aunque sea en huellas este otro mundo en el mundo que vemos en el espejo, este mundo es destruido. De esta manera aparece una trascendencia en el interior de la inmanencia cuya reconocimiento es condición de la posibilidad de la vida en el mundo visto como espejo. Marx no efectúa esta generalización, pero está en la lógica de su pensamiento. ${ }^{9}$

Como lo dijeron ya los surrealistas: hay otro mundo, pero está en este mundo.

Esta fenomenología de la vida real de Marx no hay que confundirla con las fenomenologías de Husserl o Heidegger. También estas parten de las cosas que vemos. Pero no de las cosas con las cuales vivimos. Al vivir, no podemos ver las cosas solamente en es espejo de las relaciones jurídicas como las podemos solamente vivir en este marco. No se puede ver un cerco, que está alrededor de un terreno sin ver que lo vemos en el espejo de las relaciones jurídicas. Es la expresión corporal de una voluntad que mora en aquella propiedad privada. Solamente por eso tiene sentido. En cuanto las cosas son vistas, se las ve en una relación jurídica, que 
contienen y reflejan corporalmente, no como exterritorialidad formal. En la forma de esta superficie corporal se expresa el reflejo. Tiene una expresión corporal. (ver Kafka: La colonia penitenciaria o Foucault: Vigilar y castigar) También la obra de los Pasajes de Walter Benjamin parte de eso: en este caso se trata de los productos del pasado impregnados por lo presente del pasado. ${ }^{10}$

Tampoco hay que confundir con el mundo de la vida de Habermas, que existe al lado de las estructuras y es absorbida por ellas. Se trata de eso: la ley está inscrita en el mundo corporal, pero no con letras.. El mundo corporal está marcado e impregnado por la ley.
Eso es ciertamente algo diferente que la teoría de base y superestructura del prólogo de 1859. Pero es el fundamento, a partir del cual también esta teoría puede ser interpretada.

La teoría de base y superestructura es una abstracción teórica como todas las teorías. Su aplicación es el traslado de sus resultados al mundo de la vida real. Una teoría jamás puede reflejar esta realidad, aunque sea útil en referencia a ella. El mundo de la vida real es un drama, como también Marx lo ve, y no la sombra de teorías. Por eso también las artes y los mitos son parte de la fenomenología de la vida real. La teoría es externa a este mundo.

\section{Lo imposible que mueve a lo posible}

o imposible mueve lo posible,
en cuanto que es traducido y
hecho presente.

Se puede hacer posible lo imposible en el grado en el cual se tiene la conciencia que no se puede realizarlo.

Imposibilidades abren posibilidades. Lo imposible mueve lo posible. Es el famoso "motor inmóvil" (un motor, que mueve sin estar en movimiento él). Pero ya no tiene la forma aristotélica. No es algo fuera del mundo, in el cual el ser humano actúa, sino está en el interior del mundo.

Lo imposible es objeto de la acción humana siendo un imposible en relación a esta acción.
Por eso no es algo lógicamente imposible (es lógicamente imposible que $2+2$ sea 5 ), sino en el sentido de la conditio humana (como el perpetuum mobile es imposible en sentido de la conditio humana, sin ser lógicamente imposible). Sin embargo, el perpetuum mobile como imposibilidad abrió la posibilidad del reloj del péndulo. Sin comprender la imposibilidad del perpetuum mobile no se habría podido descubrir la posibilidad del reloj del péndulo. Lo imposible abre los caminos de lo posible.

Estas imposibilidades mueven las posibilidades y hacen que sea posible descubrir posibilidades. Imposibilidades. En el sentido de la parábola de la caverna esta tra- 
ducción del imposible en posible la sombra de la luz — o de la luz fatua -que vemos desde la caverna.

Que este imposible sea efectivamente imposible, constituye la inquietud humana y con eso se transforma en aquello, que mueve lo posible. Constituye la posibilidad para descubrir lo que es posible. De esta inquietud resulta la dimensión de los posible como traducción y hacer presente de lo imposible en lo posible. Pero esta traducción no es una aproximación en el tiempo y menos una aproximación asintótica a lo imposible. Eso solamente trasladaría el problema hacia un tiempo abstracto y lineal de aproximación, que al final resulta completamente vacío.
Se trata de pasos de traducción y del hacer presente posibilidades, a los cuales en lo presente de mañana siguen otros pasos, que hoy no se puede ni prever ni determinar.

La presencia de la ausencia de "relaciones directamente sociales de las personas en sus trabajos" es lo que mueve todo el pensamiento crítico y la praxis que le corresponde. Marx usa diferentes expresiones: el trabajo como juego libre de las fuerzas corporales y espirituales; el robinsón social; el reino de la libertad; ;1 la emancipación de cada uno como condición de la emancipación de todos; la naturaleza como amiga del ser humano. En forma más bien irónica los describe:

\begin{abstract}
"...al paso que en la sociedad comunista, donde cada individuo no tiene acotado un círculo exclusivo de actividades, sino que puede desarrollar sus aptitudes en la rama que mejor le parezca, la sociedad se encarga de regular la producción general, con lo que hace cabalmente posible que yo pueda dedicarme hoy a esto y mañana a aquello, que pueda por la mañana cazar, por la tarde pescar y por la noche apacentar el ganado, y después de comer, si me place, dedicarme a criticar, sin necesidad de ser exclusivamente cazador, pescador, pastor o crítico, según los casos." Fromm, Erich: Marx y su concepto del hombre. (Karl Marx: Manuscritos económicos-filosóficos. Brevarios. FCE. México, 1964. La ideología alemana. p. 215)
\end{abstract}

Marx tiene cierta conciencia del problema de posibilidad e imposibilidad, pero aparece solamente al margen. Eso ocurre, por ejemplo, cuando insiste, que el reino de la libertad jamás podrá realizarse sustituyendo el reino de la necesidad y que, por tanto, su realización será siempre limitada. Pero no transforma eso en el fundamento de su reflexión. Concibe, por tanto, el reino de la libertad como algo, que puede surgir solamente al lado del reino de la necesidad. ${ }^{12}$ Engels es mucho menos cauteloso cuando habla del socialismo como el salto hacia el reino de la libertad. 
De eso se desarrolló la idea de la abolición de la producción mercantil y, por tanto, del mercado y del Estado. Hoy no puede haber duda, que también en este caso se trata de imposibilidades, del las cuales solamente se puede derivar la transformación de la producción mercantil y del Estado y sus democratización por una intervención sistemática en los mercados, pero jamás la realización directa de esta imposibilidad.

Hablando en general, se trata de la imaginación de lo que es la idea del comunismo en Marx y en buen grado en la tradición marxista.

Me parece, que hoy no puede haber duda de que esta imaginación desarrolla una imposibilidad. Pero no se trata de una imposibilidad cualquiera, sino de ausencias presentes en las relaciones de dominación como aquello, que no es, pero que está presente por negación y que, por tanto, puede ser derivado se ellas. Eso explica el lugar central, que la crítica de la economía política para el pensamiento crítico. De otra manera se transforma en "utópico" en el sentido crítico en el cual Marx habla del socialismo utópico.

Este comunismo como relación social directa no puede ser la meta. Una imposibilidad nunca puede ser una meta posible. Pero es lo que indica un camino, que tiene su meta en si mismo. No es la promesa de un futuro definitivo, sino el indicador en el presente desde el cual resultan los próximos pasos posibles. En este sentido muestra un futuro, pero cualquier futuro es un nuevo presente, en el cual la imposibilidad de nuevo indica el camino o las necesarias correcciones del camino. El futuro no muestra un camino, sino un camino solamente muestra el presente y en el futuro el presente de este futuro. Se trata de un camino que tiene su meta en su propio interior y en la imposibilidad, su indicador. "Se hace camino al andar". ${ }^{13}$ Cuando Bernstein dice: "La meta no es nada, el camino es todo", se pierde toda orientación. El camino tiene que ser descubierto desde lo presente y tiene como orientación la imposibilidad, que está presente como ausencia en las en las estructuras de dominación presentes. La meta es todo, el camino hay que hacerlo al andar.

\section{I El presente y el tiempo lineal}

Mañana es el presente de mañana. Pero lo presente de mañana tiene un futuro diferente del futuro de nuestro presente. Cada presente tiene su propio futuro y el presente futuro es algo, que en el mejor de los casos podemos condicionar. Cada generación hace su presente. Viendo desde su presente, tiene su propio futuro y su propio pasado. Como cada presente tiene su propia historia, también tiene su propio pasado. Al cambiar con el presente el futuro, cambia igualmente el pasado. No solamente cada generación escribe su propia historia, tiene también su propio pasado. Precisamente por eso tiene su propio futuro. Nuestro presente es el futuro de un pasado, que ha sido 
el presente antes y que ha tenido su futuro. Nuestro presente a la vez es el pasado de un presente que habrá en el futuro, como nuestro presente es el presente en el futuro de nuestro pasado. Cuando nuestro presente ha llegado a ser pasado, es algo distinto de lo que es este presente para nosotros. En la historia no hay hechos desnudos. La historia es el paso de un presente hacia otro presente por venir. Por eso no hay ningún futuro definitivo, el futuro nunca es. Lo que pensamos como futuro es nuestra reflexión sobre el desarrollo de nuestro presente al presente que le sigue. Solamente lo que en el presente dado es presente por ausencia, hace posible la orientación del paso hacia el presente futuro. Se hace el camino al andar. El futuro de cada presente es la reflexión sobre este paso. ${ }^{14}$ Eso es la imaginación del tiempo como un tiempo de vida concreto con su futuro concreto y su pasado concreto. Cualquier otro sentido del tiempo - y del futuro - es pura metafísica y por eso una imaginación abstracta, que solamente podría realizar un ser omnisciente.

La imaginación del tiempo de la teoría crítica hot clásica es la imaginación de un tiempo lineal, que es prolongado y proyectado hacia un tiempo infinito. El tiempo concreto no tiene fin, pero este tiempo proyectado al infinito es infinito. El tiempo concreto es el tiempo, en el cual sigue a nuestro presente el presente de mañana y de pasado mañana. Es el presente de mañana en el cual vivirán nuestros hijos y los hijos de sus hijos. Los presentes del pasado y del futuro están conectados en este tiempo concreto por el hecho de que de un presente a otro presente que le sigue los seres humanos tienen que vivir y deben vivir, para que siga el presente hacia el presente del futuro. En el tiempo abstracto aparecen puros futuros milagros o desgracias. Es también el tiempo de la imaginación soviética del paso al comunismo, que está ya en parte en Marx - aunque Marx sea muy cauteloso el respecto. Aparece también en Engels y está en casi todo el siguiente pensamiento marxista, muchas veces hasta hoy. Esta imaginación del tiempo también prevalece en la escuela de Frankfurt, por lo menos en lo que se Ilama hoy su primera época, a pesar de que Walter Benjamin rompe con ella. Es también la imaginación del tiempo que domina todo el pensamiento de la modernidad con su mito del progreso. Se trata, por tanto, también de la imaginación del tiempo en lo que se Ilama el progreso técnico y que hoy muy prosaicamente expresamos por las tasas de crecimiento del producto social, que también contienen una perspectiva - aunque vacía- del futuro.

A la luz de este tiempo abstracto e infinito no aparecen límites de lo posible. Nada es imposible frente a un progreso concebido como infinito en el tiempo infinito futuro. Todo lo imposible se transforma en un "todavía no" posible. Por el mito 
del progreso se transforma lo imposible - frente a un tiempo futuro arbitrariamente largo del progreso- en un aparentemente "todavía no" posible. El tiempo concreto contiene en sí imposibilidades obvias, el tiempo abstracto infinito del futuro en cambio transforma todo lo imposible en algo aparentemente posible. Con eso lo imposible es transformado en algo técnico y por eso cuantificado. En un manual soviético entonces el comunismo se ve así:

"Es preciso: prolongar la vida del hombre hasta los 150 o 200 años término medio, eliminar las enfermedades infecciosas, reducir las no infecciosas a un mínimo. Superar la vejez y el cansancio y aprender a devolver la vida a aquellos que mueren en forma prematura o por accidente... Producir todas las materias conocidas de la tierra hasta las más complicadas - las albúminas - así como también producir aquellas materias desconocidas por la naturaleza, materias más duras que el diamante, más resistentes al calor que la tierra materias con mayor temperatura de fusión que el osmio y el wolframio, más flexibles que la seda, más clásticas que la goma; criar nuevas razas de animales y cultivar nuevos tipos de plantas con un crecimiento más rápido para proveer más carne, leche, lana, cereales, fruta, fibras, madera para las necesidades de la economía del pueblo... aprender a dominar el tiempo, regular de tal modo los vientos y el calor como ahora pueden regularse los ríos, ahuyentar las nubes y llamar a voluntad a la lluvia como al buen tiempo, a la nieve y al calor"15.

Si eso son las metas, el presente de hoy y de mañana es secundario. Se trata del mito del progreso de la modernidad igual como hoy subyace a la estrategia de la globalización. Hoy se añaden otras netas infinitamente distantes como por ejemplo máquinas inteligentes y la transformación del ser humano en una máquina inteligente y otras más. ${ }^{16}$ La promesa del mito del progreso se transforma en magia.

Se trata de una imaginación del progreso en el cual toda modernidad en todas sus corrientes -incluido el socialismo soviético- orientada por el mito del progreso desemboca en la mitad del siglo XX.

Al transformarse en la Unión Soviética este mito del progreso en el mito que todo dominaba, se le adaptó la imaginación del comunismo, que se propiciaba. Perdió los contenidos humanos, que tenía en Marx, y se transformó en una imaginación de un futuro tecnificado de una planificación perfecta que podía aparentemente renunciar a 
las propias relaciones mercantiles. Las razones de la crítica que había hecho a las relaciones mercantiles desaparecieron. El comunismo fue transformado - eso se hizo visible en la discusión sobre le comunismo, a la cual Khrushev había Ilamado en los años 60- en una sociedad planificada del crecimiento económico infinito cuyo sentido es seguir con un crecimiento todavía mayor. De hecho desembocó en el mismo nihilismo que subyace hoy a la estrategia de globalización. El comunismo se transformó en una meta que está en el mismo grado más lejos en el cual se lo acerca. Con eso se desvanecía como meta. Por eso se podía después también renunciar a él y preferir el sinsentido abierto al sinsentido solapado.

La contradicción contenida en la imagen del comunismo, si se lo interpreta como un "todavía no" de su futura realización positiva, es ya reconocible en Engels:

"La propia socialización de los hombres, que hasta ahora se les enfrentó como impuesta por la naturaleza y la historia, ahora llega a ser su libre acción. Los poderes objetivos y extraños que hasta ahora dominaron la historia, pasan al control de los hombres mismos. Recién desde entonces los hombres mismos harán su historia con plena conciencia; recién desde entonces las causas movidas por ellos tendrán preponderantemente y en un grado siempre mayor, los efectos queridos por ellos. Se trata del salto de la humanidad del imperio de la necesidad al imperio de la libertad." Engels, Friedrich: Anti-Dühring. Madrid, 1968. p. 307

Lo que Engels reivindica aquí es el salto hacia una situación, en la cual se identifican el futuro de hoy con lo presente de mañana. La razón de la imposibilidad, sin embargo, es, que como consecuencia de los efectos indirectos - muchas veces no intencionales - de nuestra acción aparece la diferencia. Engels desemboca en la exigencia de una identificación de tiempo concreto y tiempo abstracto.

Pero un salto no se puede hacer "preponderantemente y en un grado siempre mayor", cuando se trata de un salto cualitativo. Al reivindicar algo imposible, tiene que interpretar pasos finitos como una aproximación a una meta infinitamente lejana. Pero eso es una contradicción, en la cual desembocó el socialismo soviética y por la cual se rompió.

El intento soviético de realizar lo humano por medio de su tecnificación y con eso en el interior del mito del progreso, probablemente ha sido el intento más serio en la historia, llevar a una solución desde el interior de la modernidad por una continuación lineal los problemas de la modernidad. Llevó a la modernidad hacia aquél punto, a partir 
del cual se hace obvio la necesidad de su propia reconstitución. Es el brillo y la miseria de este socialismo, del cual la actual estrategia de globalización no es más que una copia barata. Pero una copia: peor y posiblemente más peligrosa.

A partir de este punto se puede reconocer al mito del progreso como una catástrofe. No a donde lleva el mito del progreso o que pueda llevar a una catástrofe, es la catástrofe. Eso sería una pura inversión de este mito del progreso. Como lo hacen hoy en día los movimientos apocalípticos, sobre todo en la forma del fundamentalismo cristiano-apocalíptico, como hoy domina precisamente en los EEUU. No cambia el tiempo del propio mito del progreso, sino pone a su final la catástrofe. Proyecta la catástrofe en el tiempo lineal por venir. Al contrario la catástrofe es nuestro presente. El hecho de que sigue dominando el mito del progreso, eso es la catástrofe, como ya lo dijo Walter Benjamin. La catástrofe más bien es nuestro presente. Se trata de la catástrofe que ocurre en nuestro presente. No nos amenaza simplemente una catástrofe en el futuro. Nos amenaza la catástrofe que hoy está en curso en nuestra presencia. Esta catástrofe que proyectamos en el futuro nos subvierte desde adentro ya hoy. No vamos a la catástrofe, estamos de lleno en ella. Al proyectar la catástrofe en el futuro, estamos proyectando la catástrofe que vivimos en nuestro presente. El fundamentalismo apocalíptico fija la catástrofe en el futuro y con eso vacía el presente. La catástrofe se transforma en esperanza $(i C r i s t o$ viene!). Hablando en forma secular: hemos pasado el punto del no retorno y por eso podemos seguir, porque ya no se puede cambiar nada. La política actual del gobierno de EEU está impregnada por estos dos elementos. Con eso desaparece la responsabilidad por lo presente de mañana. El mito del progreso se da vuelta y se transforma en el mito del suicidio colectivo de la humanidad. Llega a ser el mito de la decadencia de la modernidad. El mito del progreso aparece como una supernova, que se está transformando en un hoyo negro. ${ }^{17}$

\subsection{La praxis de la traducción $y$ del hacer presente lo que es imposible}

En la crítica de la tecnificación y del vaciamiento de la imagen del comunismo surgió la filosofía de la esperanza de Ernst Bloch. Recuperó la utopía humana del comunismo y la mostró en sus más amplias ramificaciones. Con eso no volvió a aqueIla utopía que Marx había criticado en los Ilamados socialistas utópicos, sino que la concibe en el sentido de la presencia de una ausencia. Pero no vincula directamente este su análisis de la ausencia y de su presencia no con un análisis de las estructuras de dominación como eso aparece en Marx.

La filosofía de Bloch, sin embargo, resultó incapaz de fundar una praxis. Eso a mi entender resulta del 
hecho de que no deriva la utopía como algo que está presente por ausencia y negación en las propias estructuras de dominación. Cuando se lleva este análisis de la ausencia hasta el punto de ver, que puede leerse en las estructuras de dominación como presencia negada. Sin embargo, el análisis de las estructuras de dominación es la base de toda praxis. Pero a eso hay que añadir otra razón. A pesar de que Bloch recupera la utopía de Marx en sus dimensiones humanas, la sigue interpretando como un "todavía no" de la acción humana hacia el futuro. Con eso sigue comprometido con el paradigma del tiempo de la modernidad dentro del cual no existen, hacia el futuro, límites de la posibilidad. Pero precisamente este paradigma del tiempo ha impuesto a la modernidad al vaciamiento del futuro, llevó igualmente al vaciamiento de la imagen del comunismo en el socialismo soviético. Ademes es interesante el hecho de que también las filosofías de Nietzsche y de Heidegger han constatado este vaciamiento, aunque no supieron contestar a este problema.

Por el hecho de que Bloch se sigue moviendo en el marco de este paradigma del tiempo, su pensamiento no puede desarrollar una praxis. Su filosofía revela algo, pero no puede decir mucho sobre los caminos a donde ir.

Pero precisamente el redescubrimiento de la utopía de Marx de parte de Bloch tendría que llevar a la convicción que no se trata sola- mente de una utopía (lo que no hay en ningún lugar), sino también de una ucronía (lo que no hay en ningún momento del tiempo). Como tal se trata de una imposibilidad para la acción humana que es un límite infranqueable. Por eso, esta utopía no es la de un tiempo concreto. Es la utopía de una fluidez infinita de espacio y tiempo, desde la cual recién se constituye y se fundamenta el tiempo concreto en conflicto con el tiempo abstracto. Esta utopía-ucronía se encuentra en una dimensión casi mítica, que entonces exige una crítica de la razón mítica.

Esta constitución del tiempo concreto desde la utopía imposible ocurre en cuanto lo imposible es traducido y hecho presente en este tiempo concreto en conflicto con el tiempo abstracto. Se trata de un camino que se hace al andar.

La pregunta por la imposibilidad de aquello que está presente por ausencia, es la pregunta por la libertad de decidir nuestra forma de vivir. Se trata de la dimensión del sentido de vivir. En cuanto esta ausencia se cuantifica y tecnifica, entonces es proyectada como mito del progreso en la infinitud del tiempo abstracto y no quedan límites de lo posible. Lo posible es entonces ilimitadamente infinito y determina desde el futuro abstracto lo que hay que hacer. Se transforma en calor absoluto, que sacraliza todos los medios absolutamente: bueno es, lo que sirve al progreso o bueno es, lo que promueve las tasas de crecimiento. En nombre de la meta 
absoluta: bueno es lo que sirve al progreso, se pierde la libertad, el mismo ser humano se transforma en un medio para la realización de esta meta y, por consiguiente, en capital humano -en el nazismo se habló de material humano ${ }^{18}$ - y en yo-S.A. El ser humano ya no puede decidir o elegir, lo que debería ser lo presente de hoy o de mañana. El tiempo absoluto determina y lo presente se esfuma. La meta se transforma en un látigo que empuja adelante. Todo es determinado por relaciones mediofin y solamente "tontos o traidores" se pueden oponer. Todo parece ser una fuerza compulsiva de los hechos (Sachzwang). En relación con este contexto Max Weber habla de una "jaula de acero". La ideología de la actual estrategia de globalización lo expresa por la negación a cualquier intervención en el mercado. Se trata de la negación de la libertad a la autodeterminación humana. En cuanto se mantiene intacto el mito del progreso, constituye las flores que decoran el látigo. En cuanto pierde su fuerza de convicción, como ocurre hoy en gran medida, el látigo es desnudo. Sigue funcionando y llega a ser la pura voluntad del poder. Nos encontramos hoy en este proceso. En nombre de un futuro falso es oprimido el presente y con eso los seres humanos, que viven en este presente. El mito utópico del progreso transforma en mito catastrófico y con eso al capitalismo utópico en capitalismo cínico.

En cambio, el reconocimiento de la imposibilidad de lo ausente, que está presente en las estructuras de dominación, libera para la libertad como autodeterminación social. Lo imposible no puede ser transformado en nombre del "todavía no" en un fin por alcanzar, sino por el cambio de estructuras tiene que ser traducido y hecho presente. Con eso abre un espacio de posibilidades y no una sola posibilidad sin alternativas. Se trata de posibilidades entre las cuales hay que elegir y que no son predeterminadas a priori. Lo imposible se transforma el "motor inmóvil" (que mueve sin estar en movimiento él) para la acción humana, en orientación para las posibilidades que hace ver. ${ }^{19}$ Con eso es posible la libertad de autodeterminación para la formación del presente de hoy y de mañana. Se trata de una libertad conflictiva, pero no se trata de conflictos absolutos en cuanto se logra, subordinar el tiempo abstracto a las decisiones de autorealización en el tiempo concreto.

Resulta un proyecto, que puede sintetizar la totalidad de estas posibilidades: una sociedad sen la cual quepan todos los seres humanos y que da espacio igualmente a la naturaleza y que produce la riqueza de una manera tal que no sean amenazadas las fuentes de toda riqueza: la tierra y los seres humanos en cuanto trabajadores. Se trata de un proyecto democrático, porque no responde a una estrategia única y sin alternativa, sino a un conjunto de estrategias por descubrir. Lo posible como "todavía no: cierra el futuro, en cambio lo imposible 
que se traduce en posibilidad, lo abre. No puede abolir ni el mercado ni el Estado. Sin embargo, para ser realista, tiene que partir de una intervención sistemática en los mercados, que pone a este al servicio de la vida real y concreta. Con eso el ser humano no se reduce a ser individuo-propietario, sino puede llegar a ser sujeto de la vida real. En caso contrario, el humanismo sigue siendo lo que hoy es en las celebra-

\section{Notas}

1 La palabra en alemán es bedingen, lo que no significa determinar, sino condicionar. Condición en alemán es Bedingung, de lo cual se deriva el verbo bedingen. Otra palabra es entsprechen, que significa corresponder. La palabra determinar Marx no la usa para estas relaciones. Por eso, Marx no tiene una teoría de la causación de la superestructura por la base.

2 Jacques Bidet: Théorie de la Modernité. Suivi de: Marx et le Marché. Presses Universitaires de France. Paris, 1990. (en castellano: Teoría de la modernidad. Seguido de: Marx $y$ el mercado. Ediciones El cielo por Asalto. Buenos Aires, 1993.) Las citas vienen de la edición en castellano.

3 Marx, Carlos: El capital. FCE, México. p.128/129

$4 \quad$ "El trabajador no se limita a hacer cambiar la forma de la materia que le brinda la naturaleza, sino que, al mismo tiempo, realiza en ella un fin, fin que él sabe que rige como una ley las modalidades de su actuación y al que tiene necesaria- ciones públicas cuando se escucha el himno de alegría de Beethoven: pura palabrería.

De esta manera, la autorealización de cada uno puede corresponder a la autorealización de todos.

Como praxis este camino de la reconstitución del pensamiento crítico llevaría inclusive a una reconstitución de la propia modernidad y no a ninguna postmodernidad.

mente que supeditar su voluntad. Y esta supeditación no constituye un acto aislado. Mientras permanezca trabajando, además de esforzar los órganos que trabajan, el obrero ha de aportar esa voluntad consciente del fin al que llamamos atención, atención que deberá ser tanto más concentrada cuanto menos atractivo sea el trabajo, por su carácter o por su ejecución, para quien lo realiza, es decir, cuanto menos disfruta de él el trabajador como de un juego de sus fuerzas físicas y espirituales" (Marx, El capital, FCE I p.131)

Lo ausente es el trabajo como "un juego de sus fuerzas físicas y espirituales”, que se puede gozar, y cuya presencia por ausencia es tanto más intensiva, cuanto más es regido por la ley de los fines, que impone una “ atención que deberá ser tanto más concentrada cuanto menos atractivo sea el trabajo”.

$5 \quad$ Karl Marx: Manuscritos económico-filosóficos. FCE. Mexico, 1964. p.230

6 Lo mismo en el patriarcado: Como presencia de una ausencia, las relaciones de dominación del patriarcado 
revelan la igualdad de mujer y hombre. Hay que saber de esta igualdad, para poder oprimirla o negarla. Por eso también la historia del patriarcado es una historia de contradicciones internas.

"El hambre es hambre, pero el hambre que se satisface con carne guisada, comida con cuchillo y tenedor, es un hambre muy distinta del que devora carne crudo con ayuda de manos, uñas y dientes. No es únicamente el objeto de consumo, sino también el modo de consumo, lo que la producción produce no sólo objetivamente, sino también subjetivamente. La producción crea, pues, el consumidor." Marx, Karl: Elementos fundamentales para la crítica de la economía política (borrador) 1857-1858 (Grundrisse) Siglo XXI, Buenos Aires, 191971, tomo I, P.12

8 Marx, Carlos: El capital, p. 424 (ino el hombre, sino el trabajador!)

9 “...dadá es la máxima expresión de lo que George Steiner denominaría "la palabra faltante”, por la cual la poesía ya no se siente en la lengua como en su propia casa sino como en una cárcel. Hugo Ball, uno de los fundadores del café Voltaire de Zürich, justificó sus "versos sin palabras" o "poemas fonéticas" con esta contundencia: buscaba "renunciar en bloque a la lengua que el periodismo había vuelto corrupta e imposible". Edgardo Dobry, El País 29.10.05

Es lo contrario de lo que dice Heidegger cuando habla del lenguaje como la casa del ser. Para Heidegger, también el cuerpo tiene que ser la cárcel del ser.

Max Weber, en cambio, habla del capitalismo como una "jaula de acero".
Pero en nombre de su fatalismo no saca las consecuencias.

Ver Romero, José Manuel: Hacia una hermenéutica dialéctica. W. Benjamin, Th W. Adorno y F. Jameson. Sintesis. Madrid,

“A grandes rasgos, podemos designar como otras tantas épocas de progreso, en la formación económica de la sociedad, el modo de producción asiático, el antiguo, el feudal y el moderno burgués. Las relaciones burguesas de producción son la última forma antagónica del proceso social de producción; antagónica, no en el sentido de un antagonismo individual, sino de un antagonismo que proviene de las condiciones sociales de los individuos. Pero las fuerzas productivas que se desarrollan en el seno de la sociedad burguesa brindan, al mismo tiempo, las condiciones materiales para lo solución de este antagonismo. Con esta formación social se cierra, por tanto, la prehistoria de la sociedad humana." Prólogo a la contribución a la crítica de la economía política (1859). C. Marx, F. Engels: Obras escogidas. Editorial Progreso. Moscú p.183

12 "En efecto, el reino de la libertad sólo empieza allí donde termina el trabajo impuesto por la necesidad y por la coacción de los fines externos; queda, pues, conforme a la naturaleza de la cosa, más allá de la órbita de la verdadera producción material... Pero, con todo ello, siempre seguirá siendo éste un reino de la necesidad. Al otro lado de sus fronteras comienza el despliegue de las fuerzas humanas que se considera como fin en sí, el verdadero reino de la libertad, que sin embargo sólo puede florecer tomando como base 


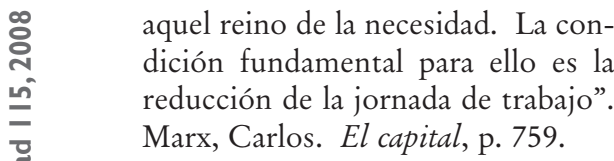

En esta argumentación no hay una presencia de una ausencia, sino que un reino existe al lado del otro.

Antonio Machado: "Caminante, son tus huellas el camino, y nada más; caminante, no hay camino, se hace camino al andar. Al andar se hace camino, y al volver la vista atrás se ve la senda que nunca se ha de volver a pisar. Caminante, no hay camino, sino estelas en la mar”.

Las estelas en la mar son el imposible que orienta.

14 Me parece que esta es la idea del tiempo que subyace a la obra de los Pasajes de Walter Benjamin. En este sentido interpreta los productos de presentes pasados. Objetivan este presente pasado en su respectivo futuro y se respectivo pasado. Con eso también sus esperanzas fracasadas. Ver Romero, José Manuel: Hacia una hermenéutica dialéctica. W. Benjamin, $T h W$. Adorno y F. Jameson. Síntesis. Madrid.

15 Grundlagen des Marxismus-Leninismus. Lehrbuch, Berlín, 1960, 825826. La traducción es mía.

16 F. J. Tipler: Die Physik der Unsterblichkeit. (La física de la inmortalidad) Munich: Piper, 1994,

Arthur C. Clark en especial su Profiles of the Future. An Enquiry into the Limits of the Possible. Londres, 1962
"According to Arthur C. Clarke any sufficiently advanced technology is indistinguishable from magic.”

Walter Benjamin escribe en sus Tesis sobre filosofía de la historia, acerca de estas ideas del tiempo:

"Los calendarios no cuentan, pues, el tiempo como los relojes. Son monumentos de una consciencia de la bistoria de la que no parece haber en Europa desde cien anos la mas leve buella. Todavia en la Revolución de julio se registro un incidente en el que dicha consciencia consiguió su derecho. Cuando llego el anochecer del primer dia de lucha, ocurrió que en varios sitios de Paris, independiente y simultáneamente, se disparo sobre los relojes de las torres. Un testigo ocular, que quizás deba su adivinación a la rima, escribió entonces:

"Qui le croirait! on dit, qu'irrités contre l'heure

De nouveaux Josués, au pied de chaque tour,

Tiraient sur les cadrans pour arreter le jour.»"

18 Recuerdo que al final de la II Guerra Mundial las locomotoras del ferrocarril alemán llevaban la siguiente inscripción: tenemos asegurada la victoria final porque tenemos el mejor material humano. Hoy la victoria final se promete a aquél que tiene el mejor capital humano. El cinismo es el mismo.

El teólogo suizo Urs Eigenmann expresa algo parecido, cuando habla del reino de Dios como criterio de compatibilidad. 